\title{
CAFFEINATED PRODUCTS CONSUMPTION AND THEIR HEALTH AND BEHAVIOR ALERTS AMONG MEDICAL STUDENTS AT BENGHAZI UNIVERSITY
}

\author{
Manal Meilad ${ }^{1}$, Sabreen Ramadan $^{2}$, Haya Hassan ${ }^{3}$, Ali Ateia Elmabsout ${ }^{4}$ \\ ${ }^{1,2,3,4}$ Department of nutrition, faculty of public health, university of Benghazi, Benghazi, Libya.
}

*Address for correspondence: Dr. Ali Ateia Elmabsout, Department of Nutrition, Faculty of Public Health, University of Benghazi, Benghazi, Libya.

Article DOI: $\underline{\text { https://doi.org/10.36713/epra8406 }}$ DOI No: 10.36713/epra8406

\begin{abstract}
Introduction: Caffeine is the most widely consumed psychoactive substance in the world and not only found in coffee, but also present in some products includes tea, energy drinks, caffeine containing medicine and soft drink. The aim of conducting the research is to study most popular caffeinated product consumption and its health and behavior alerts among medical students.

Methods: A cross sectional study was conducted from beginning of January to the end of March 2020 on branches of medical faculties involved 545 students. Purposive sampling was used to enroll students for this study and they were asked to respond to the validated questionnaires. A questionnaire related to the caffeinated products consumption and related health problems. The analysis included frequency, percentages, mean, standard deviation, unpaired T-test and ANOVA.

Result and discussion: The data collected on 545 students found that medical student consumed caffeine in the form of chocolate $87 \%$, coffee $86 \%$, Tea $74.9 \%$ soft beverages $67.2 \%$, and Arabic coffee $59.1 \%(P=0.000)$. Most of the medical student have had some reasons for drinking caffeinated products and these reasons shown significant differences $(P<0.05)$ and these reasons include $76.5 \%$ increase during exam time, about $65 \%$, to a raise level of attention and focus at the lecture and $62 \%$ for improve mood. However, students did not aware and expect the negative effect towards caffeine consumption. Based on gender, there was different on the amounts of daily caffeine intake by which male more than female $(P<0.05)$. Furthermore caffeinated products consumption significant associated with increased body weight $(P<0.05)$ There also found significant differences of caffeinated products intake among male and female $(P<0.05)$ by which male more frequent consume.

Conclusions: Drinking caffeine containing products by the students were variable from different sources. Although, students were shown consumed caffeine at modest levels. In spite, monitoring is necessary for the daily intake and there is need for educational programs about the health effects related to high consumption of caffeinated products.
\end{abstract}

KEYWORDS: malnutrition, caffeinated, BMI, Behaviors.

\section{INTRODUCTION}

Caffeine is the most widely consumed psychoactive substance in the world and not only found in coffee, but also present in some products includes tea, energy drinks, caffeine containing medicine and soft drink. (1). It has been shown that about $80 \%$ of the world's population consumes some form of caffeine daily (2).

The caffeine is 1, 3, 7-trimethylxanthine which is a natural alkaloid found in different products such as coffee, chocolate, tea, some soft drinks, and energy drinks $(3,4)$. Caffeine may activate central nervous system particularly dopaminergic reward system and thence lead to feeling of strength reinforcement (5). Caffeine is 


\section{EPRA International Journal of Research and Development (IJRD)

described as Generally Recognized as Safe (GRAS) in which caffeine intake of $3 \mathrm{mg} / \mathrm{kg}$ body weight per day are safe for adults (6).

Caffeine consumption has many beneficial effect, and one of it to be an increase performance and remain active throughout exercise by delaying fatigue and exhaustion (7). Besides, caffeine have positive relationship with performance, verbal memory, visuospatial reasoning and reaction time tasks and the effects became stronger with increasing age (8). There also found that caffeine often used to increases alertness and improves performance on tasks that required prolong level of attention (8). The recent evidences reported that caffeine can effectively used to enhance lipolysis, fat oxidation and glycogen breakdown and potent supplement to increase metabolic rate and stimulate weight loss $(9,10)$.

Current growing evidence demonstrated that low dose of caffeine will improve hedonic tone and decrease anxiety while at high dose, it can cause tense arousal such as anxiety and nervousness $(11,12)$. Furthermore, abstinence towards caffeine consumption among those who consume regularly with face symptoms of caffeine withdrawal such as detrimental effects and some other severe effects, that including greater sleepiness, poorer performance on simple reaction time, lower mental alertness, choice reaction time and recognition memory tasks (13). There are alerting that excessive intake of caffeine increase the risks of dehydration, anxiety, headache and sleep disturbances (14).

College students consumed excessive and often times dangerous levels of caffeine (15). In the study of caffeine habits among medical students found that very high percentage of caffeine consumers are among medical students and the reason beyond their consumption was consume caffeine while studying for exam to overcome stress during exams period (15) while another study reported that social consumption up to (70\%) and preference for the taste up to (72.4\%) (16) and the majorities of students consumed caffeine in any form such as tea and coffee (17).

The study conducted in undergraduate students of various medical and dental colleges in India revealed that caffeine has been demonstrated for increment of sharpness as well as alertness level of the individual (18). It has been found that caffeine has alert depending on types of caffeinated products, age and gender which ranging from high motivation in female, younger age groups, and As for the type of caffeinated products taste appeared to be equally and highly important to be considered an important finding with regard to the popularity and maintenance of caffeine consumption $(19,20)$.

To our knowledge, a in spite of this there are not much studies related to consumption of caffeine products among medical students. With this in mind the research question in a way that interested to view the response from medical students which represents the students from different branches of medical faculties in Benghazi. Libya. Therefore,

The aim of conducting the this research is to study the caffeinated products consumption among medical students and their health and behavior alerts.

\section{MATERIAL AND METHODS}

\section{Study Design and Study Time}

A cross sectional study was conducted from Beginning of January to the end of March 2020 on the students from medical faculties which have 5 branches include medicine, dental, Pharmacy, Public health and Medical Technology in Benghazi, Libya.

\section{Sample size and Sampling Method}

Purposive sampling was used as the sampling method while conducting the study, which is a nonprobability sampling method. The inclusion criteria were the medical students who voluntarily agreed to participate in the study and the questionnaires must be completed to be considered valid for the research after they filled up the consent form. Meanwhile, for the exclusion criteria, included those who did not fill upthe consent form, not available when the questionnaires were distributed, incomplete questionnaires and irrelevant responses. We distributed our questionnaires to medical students of(medicine, dental, pharmacy, public health and medical technology students. Total 545 students (181 male and 364 female) gave on hand the questionnaire and the response rate was $99 \%$.

\section{Data Collection}

The pre-validated 20 items questionnaire parts was distributed to the students. The Questionnaire containing the following items, informed consent (awareness and knowledge of the participants 'right), demographic data and the information regarding coffee consumption among undergraduate medical, health and behavior effects of caffeinated products consumptions, and Boyd weight status (BMI). Total caffeine contents of the products were collected base on the information available on the products. 


\section{EPRA International Journal of Research and Development (IJRD) \\ Volume: 6 | Issue: 9 | September 2021 \\ - Peer Reviewed Journal}

\section{Data Processing and Data Analysis}

Data was introduced to Social package for social sciences version 23 used to statistically analyses the data. For the quantitative data (Caffeine contents)the mean and standard deviation and range were calculated by using either T Test or Anova test, whereas for the qualitative data (gender, ages type of caffeinated products consumed), the frequency of those data were counted, the percentage were calculated and Chi-square test was used. The level of significant at $5 \%$ which is 0.05 .

\section{Ethical Consideration}

Participants of our study were obtained by voluntary participation. Informed consents were distributed to participants and they were asked to sign the consent forms if they voluntarily participating in our study. Furthermore, confidentiality of all data obtained from the participants were maintained. Besides, the research was conducted ethically by obtaining approval from the Local Research Ethics Committee, medical Faculties of Benghazi University, Libya.

\section{RESULTS}

The data collected on 545 students from branching of medical faculties shown that $181(33.2 \%)$ male and $364(66.8 \%)$ ) female (Figure 1). The age of the students were ranging from 20-27 years old with mean \pm SD was $23.5 \pm 5$ years old. Approximately 50\% of the students were aged between 23-25 years old followed by age groups between $20-22$ years old (42\%) (Figure 2).

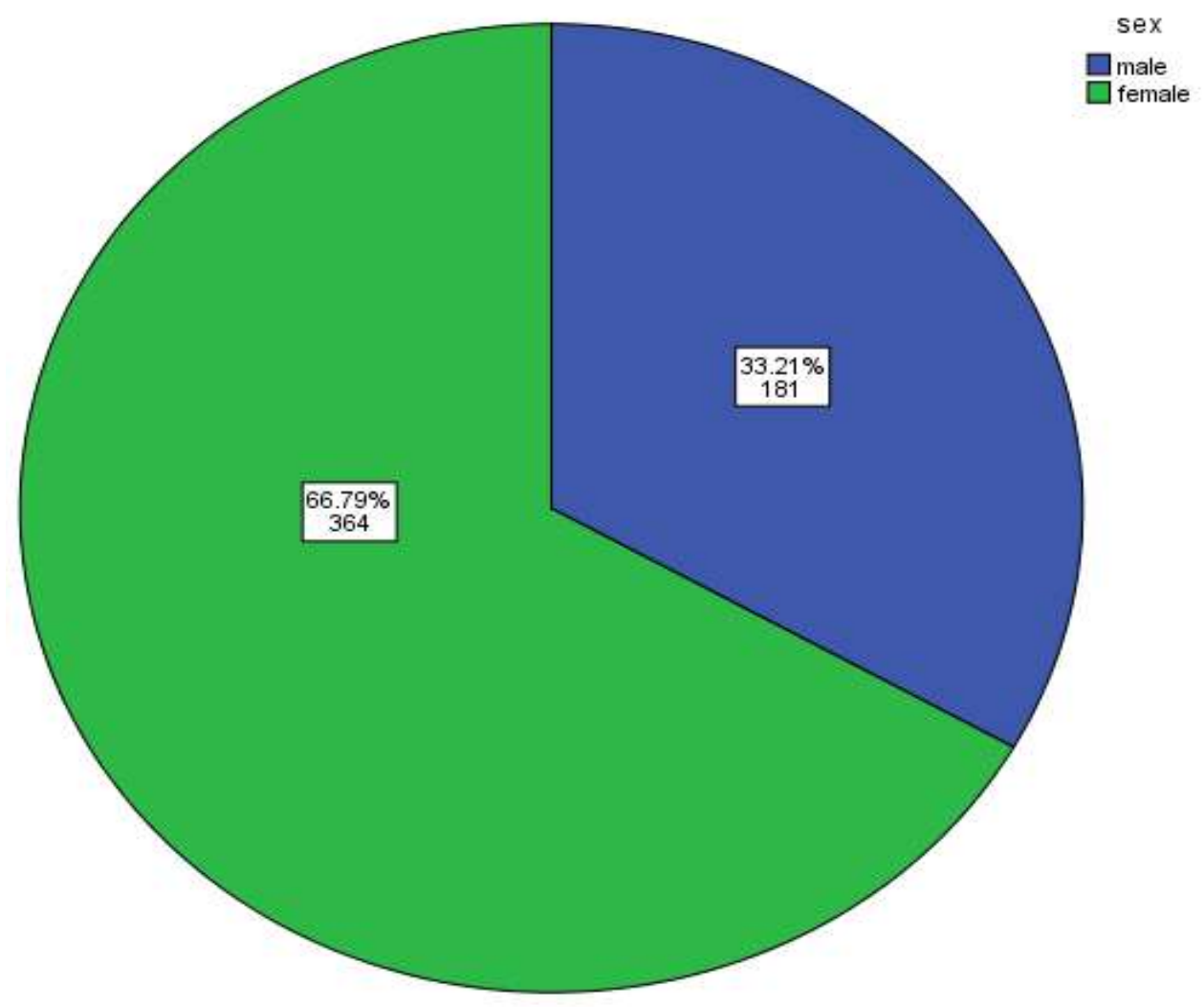

Figure 1: Gender distribution of the participants. 


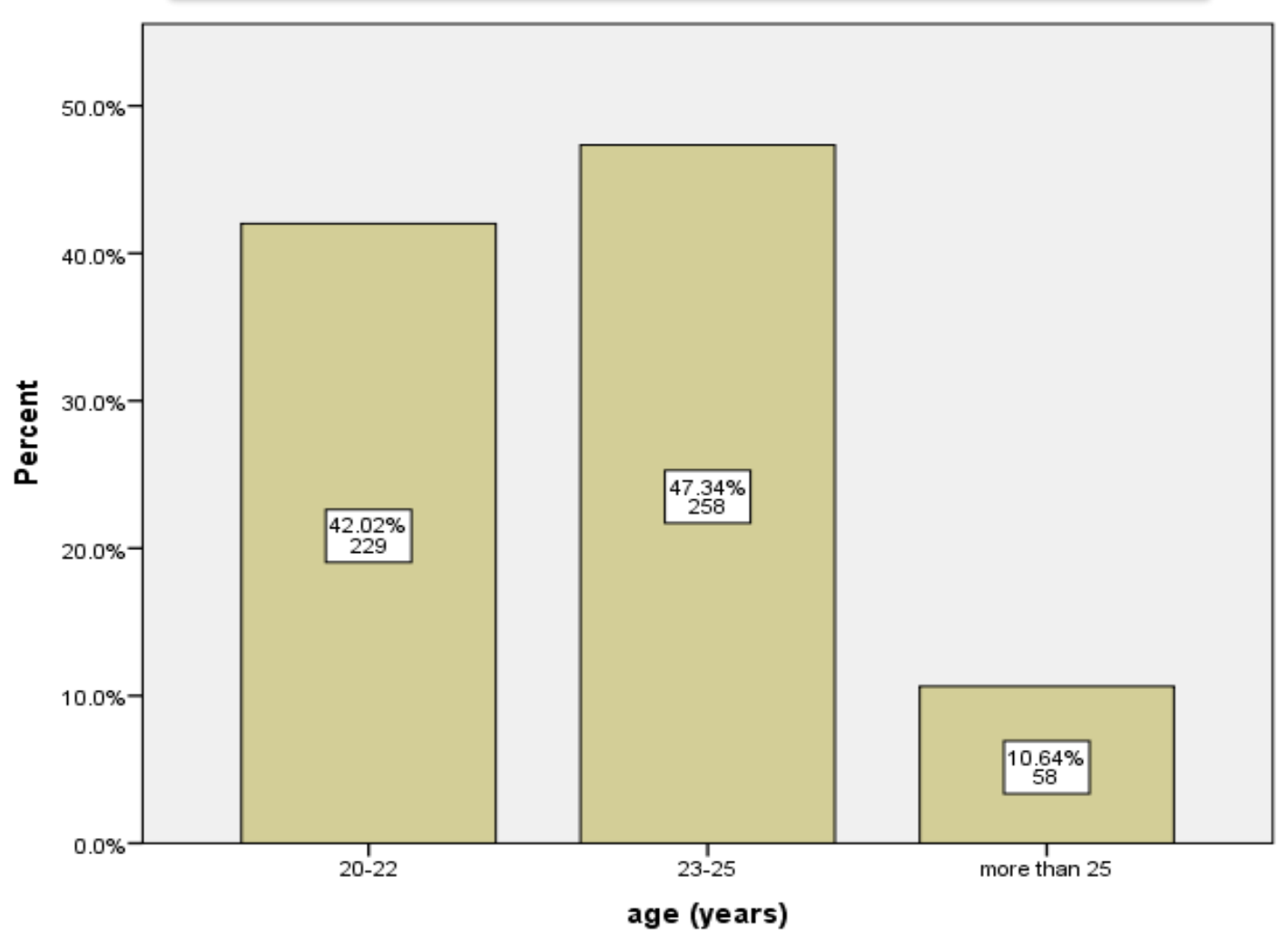

Figure 2: Age distribution of the participants.

In the next step, the data collected from branching of medical faculties were found that, more students participated in the studies were from medicine presented by about one third followed by $18.5 \%, 17.8 \%$ and $16.9 \%$ from public health and dentistry and medical technology respectively, while the Pharmacy being the lowest (11.6\%). (Table 1).

Table 1: Number of students from Branching of medical faculties:

\begin{tabular}{|l|r|r|}
\hline Branching of medical faculties & $\mathbf{N}$ & $\mathbf{N} \%$ \\
\hline Medicine & 192 & $35.2 \%$ \\
Dentistry & 97 & $17.8 \%$ \\
Pharmacy & 63 & $11.6 \%$ \\
Public Health & 101 & $18.5 \%$ \\
Medical Technology & 92 & $16.9 \%$ \\
Total & 545 & $100.0 \%$ \\
\hline
\end{tabular}

In the Table (2), the most popular caffeinated products consumed among students were found significantly high consumed include coffee, Tea, chocolate, soft beverages, and Arabic coffee $(\mathrm{P}=0.000)$ while the remaining caffeinated products not shown any trends $(\mathrm{P}>0.05)$. Further analysis of the popular caffeinated products consumed among branching of medical faculties shown same trends for coffee, Tea, chocolate, soft beverages, and Arabic coffee $(\mathrm{P}=0.000)$ by which medicine students were highly consumed students. In regard Nescafe has been shown more consumed by pharmacy and public health faculty (data not shown because not significant). 
EPRA International Journal of Research and Development (IJRD)

Volume: 6 | Issue: 9 | September 2021

- Peer Reviewed Journal

Table 2: The most popular caffeinated products consumed by the students

\begin{tabular}{|c|c|c|c|c|}
\hline \multicolumn{2}{|c|}{$\begin{array}{l}\text { Types of caffeinated } \\
\text { products consumed }\end{array}$} & $\mathbf{N}$ & N \% & P values \\
\hline \multirow[t]{3}{*}{ coffee } & yes & 469 & $86.1 \%$ & 0.000 \\
\hline & no & 76 & $13.9 \%$ & \\
\hline & Total & 545 & $100.0 \%$ & \\
\hline \multirow[t]{3}{*}{ tea } & yes & 408 & $74.9 \%$ & 0.000 \\
\hline & no & 137 & $25.1 \%$ & \\
\hline & Total & 545 & $100.0 \%$ & \\
\hline \multirow[t]{3}{*}{ chocolate } & yes & 474 & $87.0 \%$ & 0.000 \\
\hline & no & 71 & $13.0 \%$ & \\
\hline & Total & 545 & $100.0 \%$ & \\
\hline \multirow[t]{3}{*}{ soft beverage } & yes & 366 & $67.2 \%$ & 0.000 \\
\hline & no & 179 & $32.8 \%$ & \\
\hline & Total & 545 & $100.0 \%$ & \\
\hline \multirow[t]{3}{*}{ energy beverage } & yes & 86 & $15.8 \%$ & \\
\hline & no & 459 & $84.2 \%$ & \\
\hline & Total & 545 & $100.0 \%$ & \\
\hline \multirow[t]{3}{*}{ Arabic coffee } & yes & 322 & $59.1 \%$ & 0.000 \\
\hline & no & 223 & $40.9 \%$ & \\
\hline & Total & 545 & $100.0 \%$ & \\
\hline \multirow[t]{3}{*}{ Nescafe } & yes & 260 & $47.7 \%$ & 0.43 \\
\hline & no & 285 & $52.3 \%$ & \\
\hline & Total & 545 & $100.0 \%$ & \\
\hline \multirow[t]{3}{*}{ cappuccino } & yes & 103 & $18.9 \%$ & \\
\hline & no & 442 & $81.1 \%$ & \\
\hline & Total & 545 & $100.0 \%$ & \\
\hline \multirow[t]{3}{*}{ macchiato } & yes & 73 & $13.4 \%$ & \\
\hline & no & 472 & $86.6 \%$ & \\
\hline & Total & 545 & $100.0 \%$ & \\
\hline \multirow[t]{3}{*}{ espresso } & yes & 31 & $5.7 \%$ & \\
\hline & no & 514 & $94.3 \%$ & \\
\hline & Total & 545 & $100.0 \%$ & \\
\hline
\end{tabular}

Chi-square test was performed and considered significant at $\alpha<0.05$

The types of medication containing caffeine were also investigated among students (Table 3). By about $43 \%$ of the students were used panadol and being least was migraines drugs (6.4\%).

Table 3: Types of medication containing caffeine:

\begin{tabular}{|c|c|c|}
\hline Type of medicine contain caffeine & $\mathrm{N}$ & $\mathrm{N} \%$ \\
\hline panadol extra & 232 & $42.6 \%$ \\
migraine medications & 35 & $6.4 \%$ \\
not consume & 278 & $51.0 \%$ \\
Total & 545 & $100.0 \%$ \\
\hline
\end{tabular}

Furthermore, to understanding the reasons why students do preferred drink caffeinated products, a numbers of questions were prepared and predesigned and those questions were shown in Table (4). The significant answers reported by students beyond drink caffeinated products found that increased caffeinated products during examination, improved moods, increase levels of attention $(P=0.000)$. 
EPRA International Journal of Research and Development (IJRD)

Volume: 6 | Issue: 9 | September 2021

- Peer Reviewed Journal

Table 4: Reasons for caffeinated products consumptions

\begin{tabular}{|c|c|c|c|c|}
\hline \multicolumn{2}{|l|}{$\begin{array}{l}\text { Parameters } \\
\end{array}$} & $\mathbf{N}$ & $\mathbf{N} \%$ & P values \\
\hline \multirow{3}{*}{$\begin{array}{c}\text { Parameters } \\
\text { caffeine consumption increase during exam time? }\end{array}$} & Yes & 417 & $76.5 \%$ & 0.000 \\
\hline & no & 128 & $23.5 \%$ & \\
\hline & Total & 545 & $100.0 \%$ & \\
\hline \multirow[t]{3}{*}{ improve mood } & yes & 339 & $62.2 \%$ & 0.000 \\
\hline & no & 206 & $37.8 \%$ & \\
\hline & Total & 545 & $100.0 \%$ & \\
\hline \multirow[t]{3}{*}{ raise level of attention and focus at the lecture? } & Yes & 355 & $65.1 \%$ & 0.000 \\
\hline & no & 190 & $34.9 \%$ & \\
\hline & Total & 545 & $100.0 \%$ & \\
\hline \multirow[t]{3}{*}{ to stay awake } & yes & 284 & $52.1 \%$ & 0.324 \\
\hline & no & 261 & $47.9 \%$ & \\
\hline & Total & 545 & $100.0 \%$ & \\
\hline \multirow[t]{3}{*}{ usually of social habits } & yes & 149 & $27.3 \%$ & \\
\hline & no & 396 & $72.7 \%$ & \\
\hline & Total & 545 & $100.0 \%$ & \\
\hline \multirow[t]{3}{*}{ adjusting the level of blood pressure and glucose } & yes & 41 & $7.5 \%$ & \\
\hline & no & 504 & $92.5 \%$ & \\
\hline & Total & 545 & $100.0 \%$ & \\
\hline
\end{tabular}

Chi-square test was performed and considered significant at $\alpha<0.05$

The students respond to next questions related side effect of excessive caffeinated products consumed were shown in the Table (5), for the knowledge questions presented in table (5) students they likely have poor awareness and knowledge of high intake of caffeinated products by which lack of knowledge among students ranging from $55 \%$ for stomachaches to $85.7 \%$ for nausea.

Table 5: Awareness of the students for the side effect of excessive caffeinated products consumption:

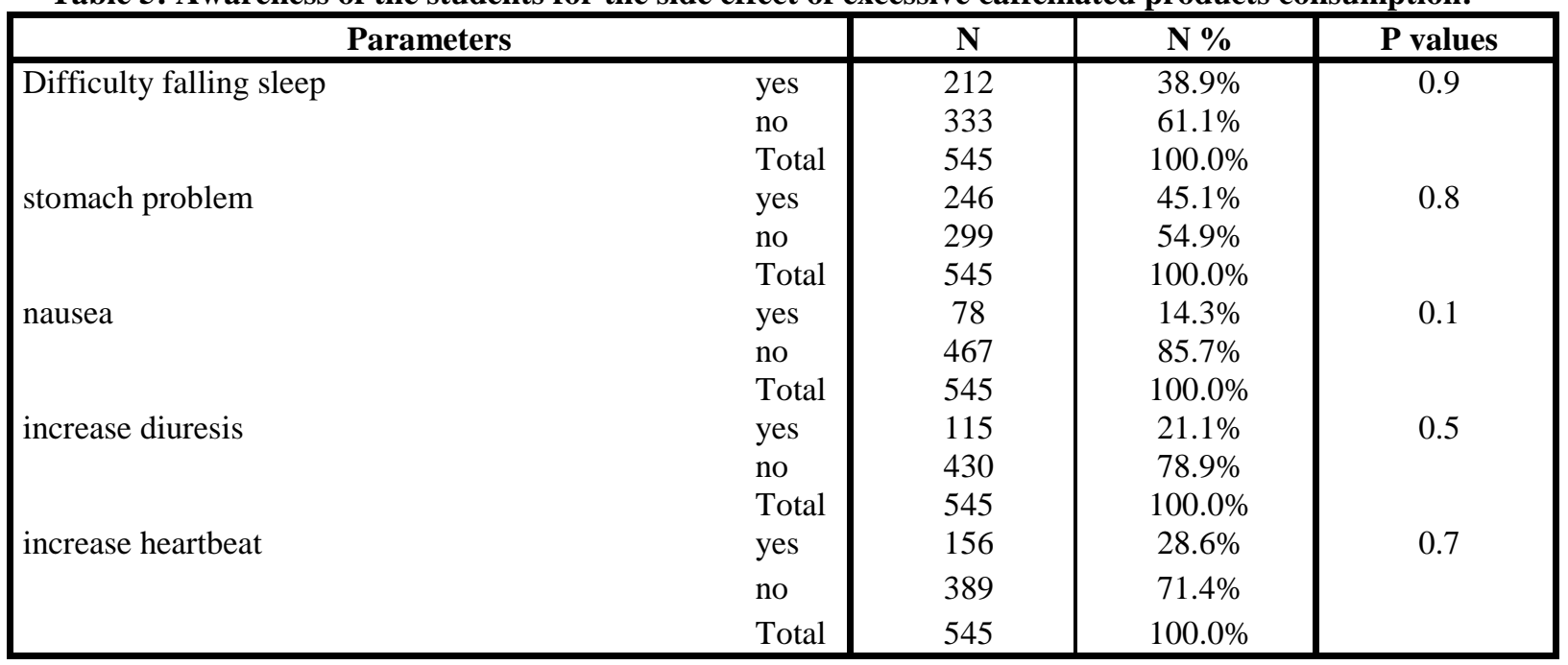

Chi-square test was performed and considered significant at $\alpha<0.05$

In the table (6), Body weight status of the students have also evaluated by body mass index. Furthermore, normal body mass index was predominate among the students $(66.1 \%)$ followed by $21.8 \%$ and $7.2 \%$ for overweight and underweight respectively. 
EPRA International Journal of Research and Development (IJRD)

Volume: 6 | Issue: 9 | September 2021

- Peer Reviewed Journal

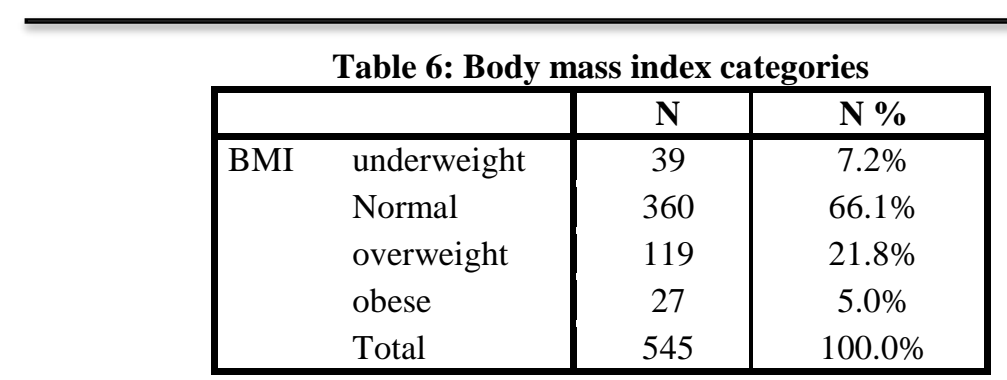

The total caffeine intake was presented in table (7) in which mean \pm SD of mg caffeine consumption was 232.3 $\pm 112 \mathrm{mg} /$ day.

Table 7: Mean caffeinated products consumed:

\begin{tabular}{|l|c|}
\hline \multicolumn{1}{|c|}{ Total caffeine consumed } & Mean \pm SD \\
\hline $\begin{array}{l}\text { Branching of medical faculties } \\
(\mathrm{mg} / \text { day })\end{array}$ & $232.33 \pm 112$ \\
\hline
\end{tabular}

The mean caffeine intake was not found significant consumed among medicine students $(P=0.447)$ compared to other branching of medical faculties. The mean caffeine consumptions was as high as in medicine, pharmacy, public health, dentistry and medical technology.

Table 8: Total caffeine intake and medical faculties branching:

\begin{tabular}{|c|c|c|c|c|c|c|}
\hline & \multicolumn{5}{|c|}{ faculties } & \multirow{3}{*}{$P$ values } \\
\hline & medicine & dentistry & pharmacy & $\begin{array}{l}\text { public } \\
\text { health }\end{array}$ & $\begin{array}{c}\text { medical } \\
\text { technology }\end{array}$ & \\
\hline & Mean \pm SD & Mean \pm SD & Mean \pm SD & Mean \pm SD & Mean \pm SD & \\
\hline $\begin{array}{l}\text { Total .caffeine } \\
\text { (mg/day }\end{array}$ & $250.57 \pm 135$ & $225.77 \pm 116$ & $244.48 \pm 124$ & $229.84 \pm 114$ & $195.61 \pm 107$ & 0.447 \\
\hline
\end{tabular}

In compared to the normal body weight, obese students were significantly consumed more caffeine $(P=0.033)$, while those underweight or overweight did not shown any trends (Table 9). Although, further investigated the consumption of caffeine among male and female shown in table (10) by which male significantly $(P=0.001)$ consumed caffeine than female (Table 10).

Table 9: BMI and Total daily caffeine consumption:

\begin{tabular}{|l|c|c|c|c|c|}
\hline \multirow{2}{*}{} & \multicolumn{3}{|c|}{ BMI } & \multirow{2}{*}{ P values } \\
\cline { 2 - 6 } & underweight & Normal & overweight & obese & \\
\cline { 2 - 6 } & Mean \pm SD & Mean \pm SD & Mean \pm SD & Mean \pm SD & 0.033 \\
\hline $\begin{array}{l}\text { Total. Caffeine } \\
\text { (mg/day) }\end{array}$ & $213.46 \pm 113$ & $218.90 \pm 121$ & $233.91 \pm 129$ & $286.78 \pm 136$ & 0 \\
\hline
\end{tabular}

Student $\mathrm{T}$ test was performed by which at $\alpha<0.05$ considered significant.

Table 10: caffeine consumption among male and female:

\begin{tabular}{|l|c|c|c|}
\hline \multirow{2}{*}{} & \multicolumn{2}{|c|}{ sex } & \multirow{2}{*}{ P values } \\
\cline { 2 - 4 } & male & female & \\
\cline { 2 - 4 } & Mean \pm SD & Mean \pm SD & 0.001 \\
\hline
\end{tabular}

Student $\mathrm{T}$ test was performed by which at $\alpha<0.05$ considered significant. 
Table 11: Relationship between caffeine consumption and reasons for caffeine products intake

\begin{tabular}{|ll|c|c|}
\hline \multicolumn{2}{|c|}{} & \multicolumn{2}{c|}{ Total. caffeine } \\
\cline { 3 - 4 } & & Mean \pm SD & P values \\
\hline 1-caffeine consumption increase during & Yes & $243.75 \pm 101$ & 0.001 \\
exam time? & no & $191.93 \pm 80$ & \\
2-improve mood & yes & $251.73 \pm 70$ & 0.005 \\
& no & $198.29 \pm 101$ & \\
3-raise level of attention and focus at the & Yes & $246.53 \pm 60$ & 0.02 \\
lecture? & no & $205.02 \pm 61$ & \\
4-stay awake & yes & $254.72 \pm 78$ & 0.03 \\
& no & $207.22 \pm 45$ & \\
\hline
\end{tabular}

$\mathrm{T}$ test has been performed between yes and no in each group and considered significant at $\alpha<0.05$.

\section{DISCUSSION}

The natural of the faculties of medicines were more female than male. The data collected on 545 students from branching of medical faculties shown that $181(33.2 \%)$ male and $364(66.8 \%)$ female. In which two fold more female than male The age of the students were ranging from 20-27 years old with mean \pm SD was 23.5 5 years old. Approximately 50\% of the students were aged between 23-25 years old followed by age groups between $20-22$ years old (42\%). The similar result for female and age predominant were also confirmed in numbers of studies conducts in Malaysia (21), UAE (22) and Pakistan (23).

In regarding branching of medical faculties in Benghazi, Libya, which is consist of 5 faculties include medicine, dental, pharmacy, public health and medical technology. In the present work one third of the students were from medicine followed by $18.5 \%, 17.8 \%$ and $16.9 \%$ from public health and dentistry and medical technology respectively, while the Pharmacy being the lowest (11.6\%). In fact our study considered first studies compile a numbers of branching of medical faculties. It could be why faculty of medicine presented the highest participants this is due to high number of students accepted at entry of university. According to data registry of the student from Benghazi university the total number of students at the faculty of medicine approximately 4000 students, while the other faculties, dental 700 students, pharmacy 900 students, public health 1400 students and medical technology 500 students and this could explained the variation in the participants.

The consumption of caffeinated products among students were reported significantly as following chocolate $87 \%$, coffee $86 \%$, Tea $74.9 \%$ soft beverages $67.2 \%$, and Arabic coffee 59.1\% $(P=0.000)$. Furthermore, these trends were also same among branching of medical faculties. For these popular products were found differently by the works done by Rajeswaran and et al (21), Bhojaraja and et al (22), El-Nimr, and et al (24), and Norton et al (25) and by which they concluded coffee or tea more frequent consumptions than other products. More than $50 \%$ of the students did not consumed medication containing caffeine, and this result inconsistent with other works $(26,27)$.

The major reasons for consuming of caffeinated products were varied and shown significant differences $(p<0.05)$, where more than tow third gave the reason that $76.5 \%$ caffeine consumption increase during exam time, about $65 \%$ to a raise level of attention and focus at the lecture and $62 \%$ for improve mood. In compared to other studies $(25,26)$ in which the reason beyond consumption of caffeinated products were due to, feel awake $(79 \%)$; enjoy the taste $(68 \%)$; the social aspects of consumption $(39 \%)$; improve concentration $(31 \%)$; increase physical energy (27\%); improve mood (18\%); and alleviate stress $(9 \%)$. However, some studies have listed such different reason $(53 \%)$, to get refreshed $(51 \%)$, taste and flavour $(49 \%)(27,28,29)$. Furthermore, the student did not aware of the symptoms of excessive caffeinated product intake ( $p>0.05)$ such as difficult falling sleep, stomachache, nausea increased diuresis and hear rates. The similar finding were also obtained by Rajeswaran and et al (21). On the other hands Bhojaraja and et al (22) and in his works reported that about $56 \%$ were of an opinion that they do experience different symptoms if they don't consume their daily caffeine intake (22).

The anthropometric measurements by BMI of the students shown that $(66.1 \%)$ were have normal body weight status and this result was inconsistent with $(30,31)$.

In the current research there was found the mean caffeine consumptions was $232.3 \mathrm{mg} / \mathrm{day}$. Caffeine is one of many constituents in foods that can exert physiological effects. Scientific and historical evidence shows that among the healthy adult population, moderate caffeine consumption (e.g., $(400 \mathrm{mg} /$ day) is not associated with adverse health effects (32). Improvements in mental alertness, concentration, fatigue, and athletic performance are well documented benefits. Modest intake of caffeine that is $200-300 \mathrm{mg}$ per day are beneficial to health (6). A safe level of daily caffeine intake is regarded as one not exceeding $400 \mathrm{mg}$ per day (6). Excessive daily intake above $400 \mathrm{mg}$ may however cause agitation, sleep disturbances, anxiety, irritability, 


\section{EPRA International Journal of Research and Development (IJRD)

nervousness (3). A regular, long term and excessive intake may lead to an addiction and adverse health consequences. 1 Caffeine, like sugar, may activate the dopaminergic reward system and thence lead to addiction. The adverse health effects of caffeine are even more apparent in sensitive populations, namely children and adolescents.

In 1978, the Food and Drug Administration (FDA) classified caffeine as a Multiple Purpose Generally Recognized as Safe Food Substance, with tolerance at 0.02\% (200 part per million [ppm]), stating that moderate caffeine intake produces no increased risk to health.(16) In 2015, the European Food Safety Authority (EFSA) suggested that consuming caffeine up to $200 \mathrm{mg}$ (about $3 \mathrm{mg} / \mathrm{kg}$ body weight) from all sources do not raise safety concerns for the general adult population (17).

The mean caffeine consumptions was as high as in medicine, pharmacy, public health, dentistry and medical technology students. However these finding was not statistically significant $(P=0.447)$. The association between caffeine intake and body weight revealed that increase caffeine intakes have significant relationship with increased body weight $(\mathrm{P}<0.05)$ and this result was controversial with number of studies $(27-29)$ by which increase caffeine intake led to decreased or maintaining body weight. On the other hands some researcher shown that increased caffeine consumptions result in an increased body weight (32). Furthermore, male shown significant increase consumption of caffeine than female $(271 \mathrm{vs} 213 \mathrm{mg} / \mathrm{dy})(P=0.001)$ and this were also established in number of studies $(33,34)$. There was strong relationship between caffeine consumption $(\mathrm{p}<0.05)$ and reasons beyond its consumption such as increased caffeinated products during examination, improved moods, increase levels of attention.

Overall, drinking caffeine containing products by the students are variable from different sources, so monitoring is necessary for the daily intake and there is need for educational programs about the health effects related to high consumption of caffeine. Its highly recommended that caffeine intake should be regularly monitoring among the students in order to avoid caffeine toxicity.

\section{CONCLUSION}

The present study revealed that female gender and age groups between 23-25 were more predominant in the study. More than one third of the student from faculty of medicine. Consumption of caffeinated products among students were reported significantly as following chocolate $87 \%$, coffee $86 \%$, Tea $74.9 \%$ soft beverages $67.2 \%$, and Arabic coffee 59.1\%. Although, there were significant reasons reported by students for caffeinated products consumptions in which more than tow third gave the reason that caffeine consumption increase during exam time, about $65 \%$ to a raise level of attention and focus at the lecture and $62 \%$ for improve mood. There were no significant differences and awareness in data for symptoms of excessive caffeinated products consumptions among the students. More than $66 \%$ of the students have normal body weight. The result of the present works were also shown mean caffeine consumption was $232.3 \mathrm{mg} /$ day which is considered safe. There also shown mean caffeine consumptions was as high as in medicine, pharmacy, public health, dentistry and medical technology students. Increase caffeine intakes have significant relationship with increased body weight and male shown significant increase consumption of caffeine than female ( $271 \mathrm{vs} 213 \mathrm{mg} / \mathrm{dy}$ ). The current work proved that strong relationship between caffeine consumption and reasons beyond its consumption such as increased caffeinated products during examination, improved moods, increase levels of attention.

Taken together this result suggested that Drinking caffeine containing products by the students are variable from different sources, so monitoring is necessary for the daily intake and there is need for educational programs about the health effects related to high consumption of caffeine.

\section{REFERENCES:}

1. Temple, J., Bernard, C., Lipshultz, S., Czachor, J., Westphal, J. and Mestre, M, the Safety of Ingested Caffeine: A Comprehensive Review, Frontiers in Psychiatry. 2017; 8: 80.

2. Wierzejska R. Caffeine - common ingredients in a diet and its influence on human health. Rocz Panstw Zakl Hig. 2012;63:141-7.

3. Whalen DJ, Silk JS, Semel M, Forbes EE, Ryan ND, Axelson DA, Birmaher B, Dahl RE. Caffeine consumption, sleep and affects in the natural environments of depressed youth and healthy control. J Pediat Psychol. 2008;33:358-67.

4. Tom M. McLellan, John A. Caldwell, Harris R. Lieberman, A review of Caffeine's Effects on Cognitive, Physical and Occupational Performance, Neuroscience \& Biobehavioral Reviews. 2016; 71: 294-312.

5. Kyujin Han, Jiyeon Lee, Bo Yoon Choi, Hamin Jeong, Jae Hoon Cho, Jin Kook Kim, Does Improved Attention Induced by Caffeine Intake Affect Olfactory Function?, Clinical and Experimental Otorhinolarngology. 2019;23:233-240

6. Jay R. Hoffman, Caffeine and Energy Drink, Strength And Conditioning Journal. 2010; 32: 15-20.

7. Astrid Nehlig, Is Caffeine a Cognitive Enhancer?, Journal of Alzheimer's disease. 2010; 20: S85-S94. 


\section{EPRA International Journal of Research and Development (IJRD)}

8. Rogers, P., Heatherley, S., Mullings, E. and Smith, J. Faster but not smarter: effects of caffeine and caffeine withdrawal on alertness and performance, Psychopharmacology. 2012; 226: 229-240.

9. Frary CD, Johnson RK, Wang MQ. Food sources and intakes of caffeine in the diets of persons in the United States. J Am Diet Assoc.2005.105:110-113.

10. Turnbull D, Rodricks JV, Mariano GF. Neurobehavioral hazard identification and characterization for caffeine. Regul Toxicol Pharmacol 2016;74:81e92.

11. Mrvos RM, Reilly PE, Dean BS, Krenzelok EP. Massive caffeine ingestion resulting in death. Vet Hum Toxicol.1989.31: 571-572.

12. Nowak D, Jasionowski A. Analysis of the Consumption of Caffeinated Energy Drinks among Polish Adolescents. Int J Environ Res Public Health. 2015;12:7910-21.

13. Lopez-Garcia E, van Dam RM, Rajpathak S, et al. Changes in caffeine intake and long-term weight change in men and women. Am J Clin Nutr 2006;83:674-680.

14. Gavrieli A, Yannakoulia M, Fragopoulou E, et al. Caffeinated coffee does not acutely affect energy intake, appetite, or inflammation but prevents serum cortisol concentrations from falling in healthy men. J Nutr 2011;141:703-707.

15. Reissig CJ, Strain EC, Griffiths RR. Caffeinated energy drinks - a growing problem. Drug Alcohol Depend. 2009;99:1-10.

16. U. S. Food and Drug Administration (FDA). Maryland: the Administration. USA: FDA; 2015 [cited 2016 Jan 15]. USFDA; [about 5 screens]. Available from: http://www.fda.gov/Food/IngredientsPackagingLabeling/GRAS/SCOGS/ucm256650.html.

17. European Food Safety Authority (EFSA). Panel on Dietetic Products, Nutrition and Allergies (NDA). Scientific Opinion on the safety of caffeine. EFSA J. 2015;13:4102-222.

18. Emond JA, Gilbert-Diamond D, Tanski SE, Sargent JD. Energy drink consumption and the risk of alcohol use disorder among a national sample of adolescents and young adults. J Pediatr 2014;165:1194e200.

19. Whalen DJ, Silk JS, Semel M, Forbes EE, Ryan ND, Axelson DA, Birmaher B, Dahl RE. Caffeine consumption, sleep and affects in the natural environments of depressed youth and healthy control. J Pediat Psychol. 2008;33:358-67.

20. Farag NH, Whitsett TL, Mckey BS, Wilson MF, Vincent AS, Susan AE, et al. Caffeine and blood pressure response: sex, age and hormonal status. 2010; 19:1171-6.

21. Sowmiya Rajeswaran et al.: A Cross Sectional Study on Caffeine Consumption and Caffeine Expectancy Among Undergraduate Medical Students. American Journal of Food Science and Health.2020; 6: 12-22

22. Bhojaraja VS, Janardhan H, Hameed NA, Gulsoom FAR, Ali MZ. Knowledge, attitude and practices towards consumption of caffeine containing drinks among the student population of Ras al-Khaimah medical and health sciences university, UAE. Int J Res Med Sci 2016;4: 3537-41

23. Khan MS, Nisar N, Naqvi SAA, Nawab F. Caffeine Consumption and Academic Performance among Medical Students of Dow University of Health Sciences (DUHS), Karachi, Pakistan, An-nals ASH KM\&DC. 2017; 22: 817.

24. El-Nimr NA, Bassiouny SH, Tayel DI. Pattern of caffeine consumption among university students. JHIPH. 2019;49:154-161

25. Norton TR, Lazev AB, Sullivan MJ. The "buzz" on caffeine: patterns of caffeine use in a convenience sample of college students. J Caffeine Res 2011;1:35e40.

26. Rocz Panstw Zakl Hig. university students surveyed for drinking beverages containing caffeine. BMC.2014;65:113-7.

27. Kopacz A, Wawrzyniak A, Hamułka J, Górnicka M. Evaluation of energy drink intake in selected student groups. Rocz Panstw Zakl Hig. 2013;64:49-53.

28. Jacob S, Tambawel J, Trooshi FM, Alkhoury Y. Consumption pattern of nutritional health drinks and energy drinks among university students in Ajman, UAE. Gulf Medical Journal. 2013;2:22-6.

29. C.R. Mahoney et al. Intake of caffeine from all sources and reasons for use by college Students. Clinical Nutrition. 2019. 38. 668 e675.

30. Kim, J.H.; Park, Y.S. Light coffee consumption is protective against sarcopenia, but frequent coffee consumption is associated with obesity in Korean adults. Nutr. Res. 2017, 41, 97-102.

31. Bouchard, D.R.; Ross, R.; Janssen, I. Coffee, tea and their additives: Association with BMI and waist circumference. Obes. Facts. 2010, 3, 345-352.

32. Dalia I Tayel, Samar M Abo-Rhyem, Doaa Tawfik. Caffeine content of products in Egyptian markets and its daily intake among Alexandria University employees. International Journal of Food Science and Nutrition. 2018; 3. 1421

33. Frary CD, Johnson RK, Wang MQ. Food sources and intakes of caffeine in the diets of persons in the United States. J Am Diet Assoc. 2005; 105:110-3.

34. Larsen, S.C.; Mikkelsen, M.L.; Frederiksen, P.; Heitmann, B.L. Habitual coffee consumption and changes in measures of adiposity: A comprehensive study of longitudinal associations. Sci. Rep. 2018, 42, 880-886. 